\title{
ARGILOMINERAIS DO GRUPO CAIUÁ
}

\author{
LUIZ A. FERNANDES ${ }^{* *}$, ARMANDO M. COIMBRA****, MAX BRANDT NETO***** e ANA L.D. GESICKI***
}

\begin{abstract}
CLAY MINERALS OF THE CAIUÁ GROUP. Recent studies carried out in the west of São Paulo and northwest of Paraná states (Brazil) have lead to the characterization of clay minerais of Caiuá Group (Late Cretaceous, Bauru Basin) origin and their génesis, as well as the diagenetic evolution of sandstones of the Rio Paraná Formation. The most frequent clay minerais are smectite and kaolinite, which occur in similar quantities. Illite occurs secondarily in Adamantina Formation (Bauru Group). Kaolinite predominates in surface sample rocks whereas authigenic smectite is more common in subsurface samples (Rio Paraná Formation). Diagenesis of sandstones of Rio Paraná Formation was generally not very intense and reached only the initial stages of mesodiagenesis.
\end{abstract}

Keywords: Diagenesis, Bauru Basin, late cretaceous of Brazil, eolic sandstones.

RESUMO Estudos desenvolvidos no extremo oeste do Estado de São Paulo e noroeste do Paraná permitiram caracterizar a mineralogia e génese dos argilominerais do Grupo Caiuá (Ks), bem como a evolução diagenética dos arenitos eólicos da Formacão Rio Paraná. Os argilominerais mais frequentes são esmectita e caulinita. A illita ocorre de modo secundảrio, com maior frequência na Formação Adamantina, unidade de posição mais marginal da área de estudo, pertencente ao Grupo Bauru. A caulinita, dominante em superfície, formou-se por intemperismo superficial. Em subsuperfície predominam esmectitas autigênicas. Os arenitos da Formação Rio Paraná (Grupo Caiuá) foram submetidos a transformacões pouco intensas, atingindo estágios iniciais da mesodiagênese. Vestígios de compactação química são menos comuns, em parte possivelmente refreada pela cimentação carbonática. A ação de processos de dissolução do cimento e de grãos menos estáveis é revelada pela coexistência de porosidade secundaria e feições de compactação química.

Palavras-chave: Diagênese, Bacia Bauru, cretáceo superior brasileiro, arenitos eólicos.

INTRODUÇÃO Os resultados de análises e interpretações ora apresentados são produto de estudos regionais desenvolvidos no extremo oeste do Estado de São Paulo e noroeste do Paraná (Fernandes 1992), em áreas de exposição da cobertura sedimentar suprabasáltica neocretácea (Fig. 1). Referem-se à caracterização e génese de argilominerais do Grupo Caiuá, bem como a evolução diagenética dos arenitos eólicos da Formação Rio Paraná, com eventuais referências a demais formacões que compõem o Grupo Caiuá (Formações Goio-Erể e Santo Anastácio) e ainda parte da Formação Adamantina (Grupo Bauru), devido às suas relações de contiguidade física lateral e contemporaneidade admitida.

A cobertura suprabasáltica neocretácea é constituída por rochas sedimentares de origem continental, localmente com vulcânicas associadas, acumuladas na Bacia Bauru, uma depressão tectônica evoluída entre o Turoniano e o Maastrichtiano (Ks), no centro-sul da Plataforma Sul-Americana (sobre a porção setentrional da Bacia do Paraná). Esta sequência é composta por dois grupos cronocorrelatos (Fernandes \& Coimbra, submetido): Caiuá (Formações Goio Erê, Rio Paraná e Santo Anastácio) e Bauru (Formações Adamantina, Uberaba, Marília e Analcimitos Taiúva). $\mathrm{Na}$ área dos estudos ocorre apenas parte destas unidades - arenitos essencialmente finos a muito finos do Grupo Caiuá, arenitos finos e lamitos silto-arenosos da Formação Adamantina (Grupo Bauru) - estratigraficamente relacionadas, conforme ilustra a figura 2 .

MÉTODOS DE ANÁLISE Os argilominerais foram analisados por difração de raios $\mathrm{X}$ e com microscópio eletrônico de varredura.

Para difração de raios X confeccionou-se lâminas com material decantado de suspensão obtida por sifonamento (partículas menores que $0,004 \mathrm{~mm}$ ) após pipetagem das frações entre 0,062 e $0,004 \mathrm{~mm}$. Eventualmente, utilizou-se aquecimento a $400^{\circ} \mathrm{C}$ por duas horas e tratamento com etilenoglicol,

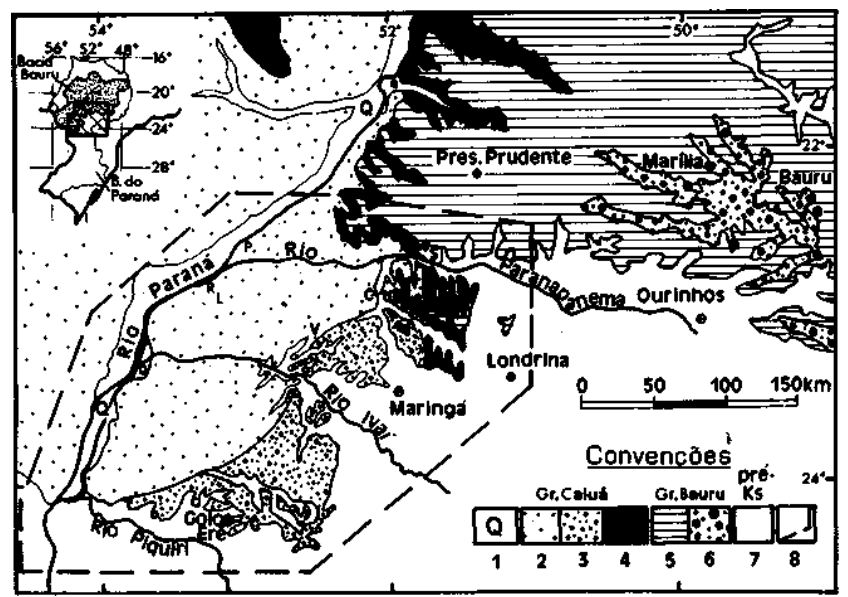

Figura 1 -Área principal de estudos e seu contexto geológico. Convenções: 1. depósitos quaternários; 2-4. Grupo Caiuá (2. Fr. Rio Paraná, 3. Fm. Goio Erê e 4. Fm. Santo Anastácio); 5-6. Grupo Bauru (5. Fm Adamantina e 6. Fm. Marilia); 7. unidades pré-Ks; 8. limite da área de estudos. Outras localidades menores: C. Colorado, L. Loanda, P. UHE Porto Primavera, $\boldsymbol{R}$. Porto Rico, S. Santo Inácio e V. Paranavai

Figure 1 - Main studied área and its geological setting. Key: I.Quaternary deposits; 2-4.Caiuá Group (2. Rio Paraná Fm., 3. Goio Erê Fm. and 4. Santo Anastácio Fm.); 5-6.Bauru Group (5. Adamantina Fm. and 6. Marilia Fm.); 7. pre-Late Cretaceous units; 8. limit of studied área. Other small localities: C. Colorado, L. Loanda, P. Porto Primavera Hydroelectric Plant, R. Porto Rico, S. Santo Inácio and V. Paranavaí

\footnotetext{
* Desenvolvido com apoio da FAPESP (Projeto Geologia 87/2722-7)

** Instituto de Pesquisas Tecnológicas do Estado de São Paulo, Caixa Postal 7141, CEP 01064-970, São Paulo, SP, Brasil, Fax (011) 8696383 *** Instituto de Geociências, Universidade de São Paulo, Caixa Postal 11348, CEP 05422-970, São Paulo, SP, Brasil, Fax (011) 2104958 **** Departamento de Química e Geociências, Universidade Estadual Paulista, Caixa Postal 136, CEP 15061-080, São José do Rio Preto, SP, Brasil
} 


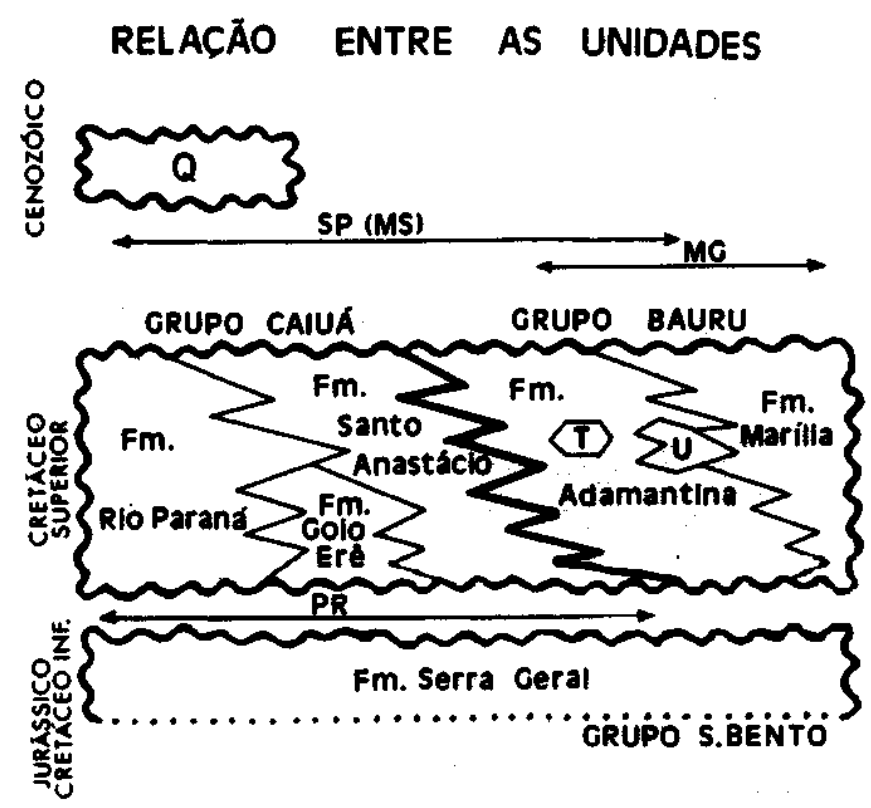

Figura 2 - Quadro de relações estratigráficas, entre as unidades neocretáceas. Convenções: T. Analcimitos Taiúva; U. Fm. Uberaba (Fernandes \& Coimbra, submetido) Figure 2 - Late Cretaceous units stratigrafic chart. Key: T. Taiú va analcimites; U. Uberaba Fm. (Fernandes \& Coimbra, subm.)

como testes suplementares na identificação dos minerais. $\mathrm{Na}$ preparação das amostras não se empregou substâncias desfloculantes, para evitar interferências nos resultados. Os difratogramas obtidos permitiram a identificação e quantificação relativa dos argilominerais presentes.

Na identificação da origem dos argilominerais - detrítica ou autigênica- contou-se com microscópio eletrônico de varredura, com capacidade de aumento até 10.000 vezes. Para a análise foram preparados, em suporte apropriado, corpos de prova com alguns milímetros, encobertos com películas de carbono e ouro (por vaporização de eletrodos em alto vácuo). A superficie deste corpo foi observada mediante sistema com câmera de TV e fotografada.
CONTEXTO DEPOSICIONAL A sedimentação da sequência siliciclástica neocretácea desenvolveu-se sob clima semi-árido a árido, em ambiente desértico para o interior da bacia (Fernandes 1992). Tal sequência é formada por depósitos de três sistemas principais: a. leques aluviais marginais: Formação Marília, nas bordas leste e norte da bacia; b. fluvial entrelaçado, com planícies de inundação com lagoas efémeras: Formação Adamantina no centro e nordeste, e Formação Uberaba (com contribuição vulcânica), no extremo nordeste da bacia; c. eólico central: Grupo Caiuá no centro/sudoeste da bacia, com a Formação Santo Anastácio - depósitos de extradunas (lençóis de areia, wadis e sabkhas - e Formações Rio Paraná: depósitos da área central de sand sea, e Goio Erê: da periferia do paleodeserto.

A figura 3 apresenta a distribuição de sistemas deposicionais na Bacia Bauru.

ARGILOMINERAIS: APRESENTAÇÃO E DISCUSSÃO DOS RESULTADOS Foram analisadas 79 amostras de superfície das três formações que compõem o Grupo Caiuá e 52 amostras de subsuperfície, apenas da Formação Rio Paraná. A título de referência, uma vez que constitui unidade relativamente pouco aflorante na área de estudo, foram também analisadas 65 amostras da Formação Adamantina (Grupo Bauru).

A quantidade de argila nos arenitos analisados é pequena, não ultrapassando porcentagens, em geral, entre 10 e $15 \%$. vezes é até mesmo ausente. Quanto à génese, foram identificados três tipos de argilominerais: a. detrítico, originado como matriz; b. autigênico, formado pela transformação de minerais menos estáveis (feldspatos e argila detrítica da matriz, Fotos 1 e 2), precipitado no espaço poroso; e c. intempérico, oriundo de processos superficiais. Os argilominerais autigênicos podem constituir bons indicadores paleoambientais, notadamente aqueles formados durante a deposição ou na diagênese precoce/eodiagênese (présoterramento).

Entre os arenitos Caiuá, o argilomineral maisfreqüente é esmectita, presente como revestimento de paredes dos poros intergranulares, observados em seções delgadas (Foto 3) e com microscópio eletrônico de varredura (Fotos 4 e 5).

Nas amostras provenientes de sondagens (Formação Rio Paraná), a frequência de ocorrência de esmectitas, principal-

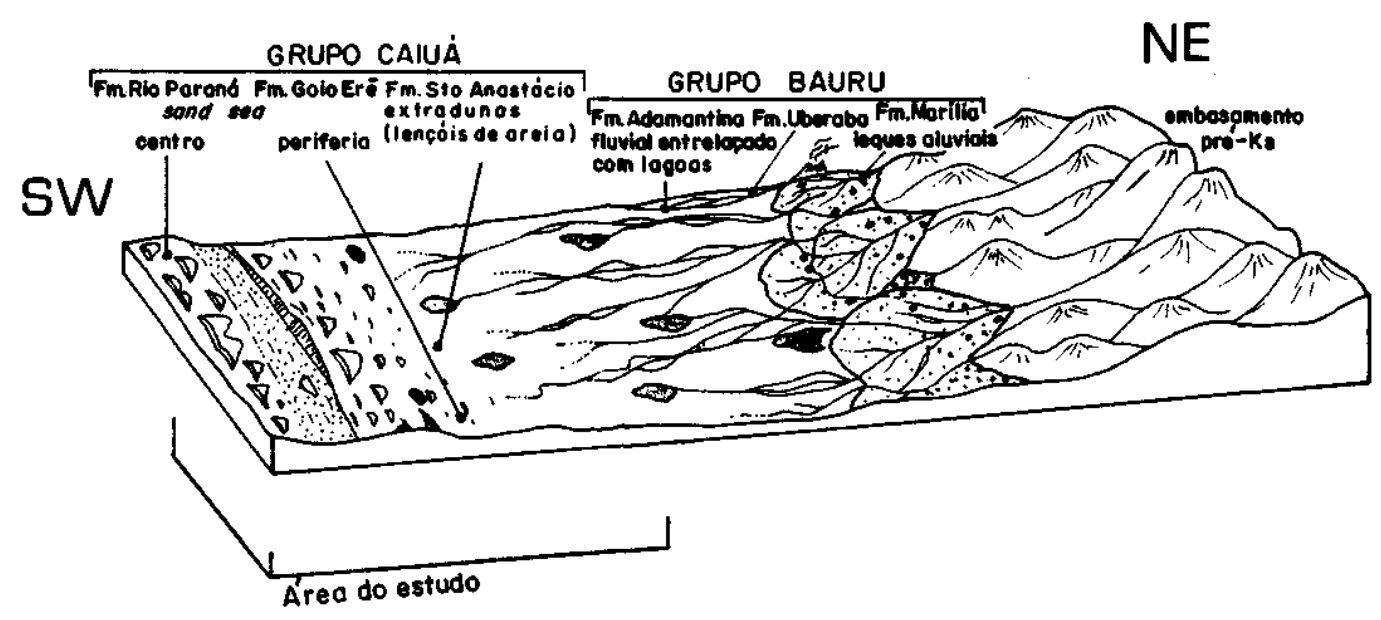

Figura 3 - Distribuição dos sistemas deposicionais na Bacia Bauru

Figure 3 - Depositional systems distribuition in the Bauru Basin 

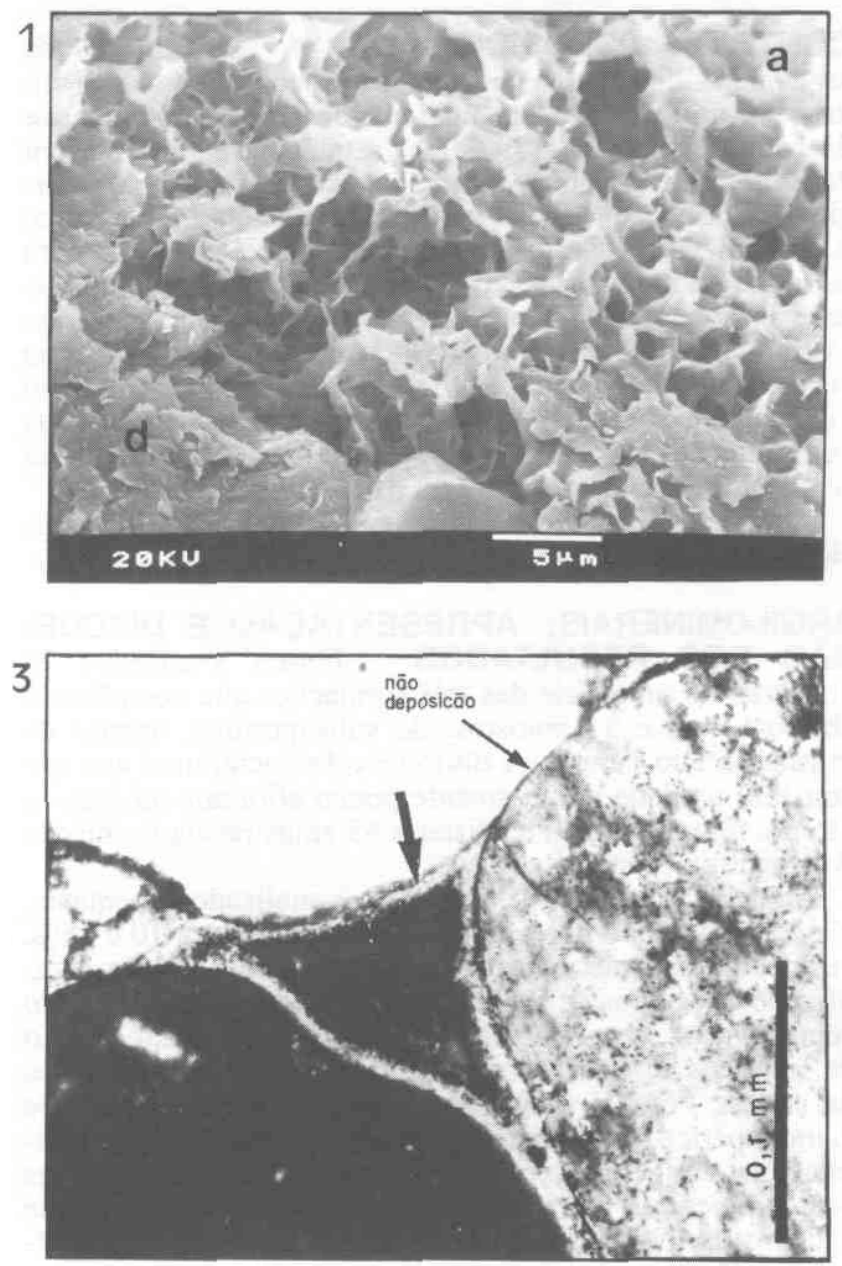
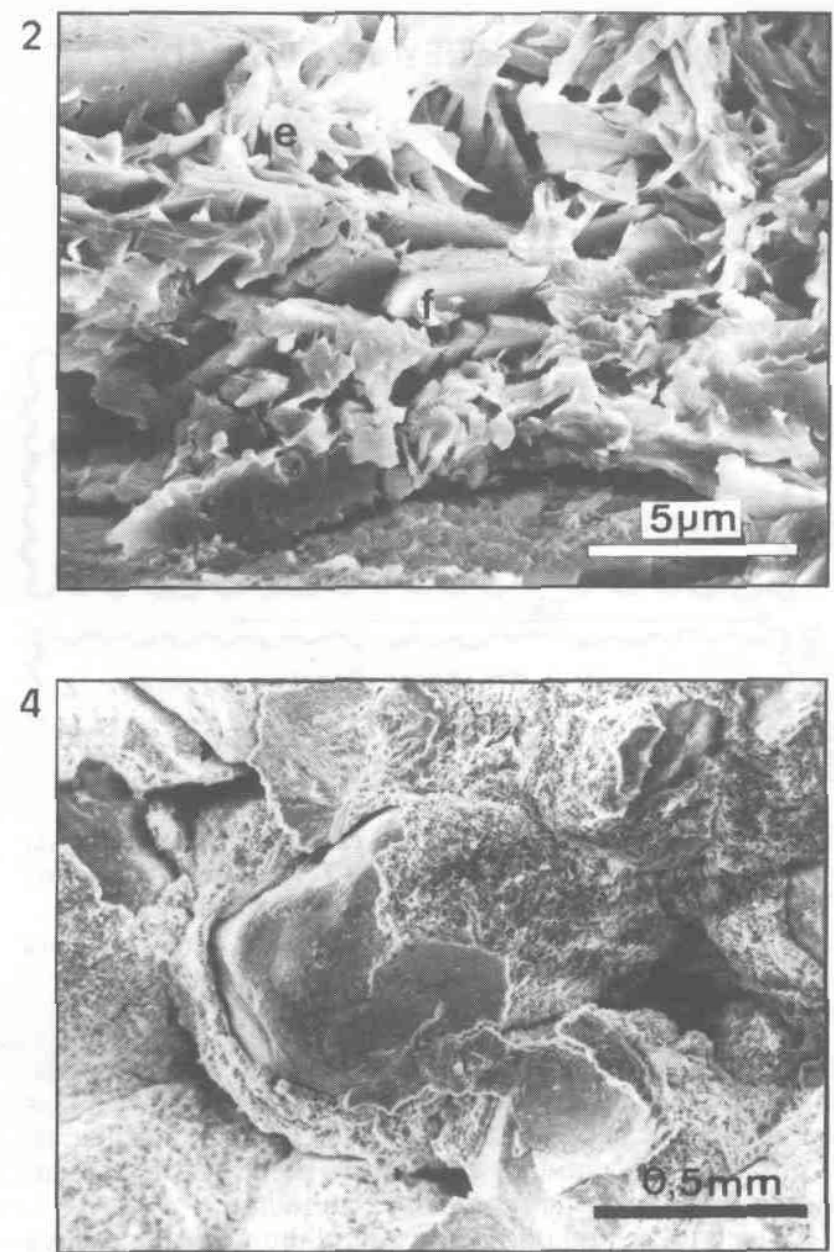

Prancha 1 -Foto 1. Esmectita detrítica (d, à esquerda) passando a autigênica (a, à direita). Imagem obtida em M.E.V. Formação Rio Paraná, amostra de subsuperficie (UHE Porto Primavera, SP). Foto 2. Feldspato (f) alterando-se em esmectita autigênica (e). Imagem obtida em M.E.V. Formação Rio Paraná, amostra de superfície (Cianorte, PR). Foto 3 Revestimento de espaços intergranulares por esmectita autigênica (seta grossa). No contato entre grãos, onde só ocorre um filme de óxido de ferro (seta fina), esta película envolve totalmente os grãos, indicando cimentação pré-soterramento. Fotomicrografia de seção delgada, com nicóis cruzados. Formação Rio Paraná, amostra de superficie (Porto Rico, PR). Foto 4. Esmectita autigênica revestindo grãos detríticos arredondados. Imagem obtida em M.E. V. Formação Goio Er ê, amostra de superficie (Goio Erê, PR)

Plate 1 - Photo 1. Detrital (d, on the left) changing to authigenic smectite (a, on the right). SEM image of subsurface sample of Rio Paraná Formation (Porto Primavera Hydroelectric Plant, São Paulo State). Photo 2. Feldspar (f) replaced by authigenic smectite (e). SEM image of outcrop sample of Rio Paraná Formation (Cianorte, Paraná State). Photo 3. Authigenic clay pore lining (bold arrow). On the contacts between the grains, where occurs only a Fe oxide film (fine arrow), this pellicle involves the grains totally, indicating pre-burying cementation. Photomicrography of thin section, crossed polarizers. Outcrop sample of Rio Paraná Formation (Porto Rico, Paraná State). Photo 4. Pore lining of detrital rounded grains by authigenic smectite. SEM image of Goio Erê Formation, outcrop sample (Goio Erê, Paraná State)

mente autigênicas, é visivelmente maior que a de caulinitas. Verifíca-se, ainda, a associação comum de esmectitas com cimentação carbonática e calcretes, que sugere condições deposicionais com pouca circulação de água, de $\mathrm{pH}$ alcalino, como as encontradas em sabkhas continentais.

A caulinita (Fotos 6 a 8) ocorre com maior frequência em amostras de superficie - de todas as unidades analisadas, denotando génese por intemperismo superficial. Tal origem reflete processos determinados pelas condições climáticas atuais (tropical úmido), distintas das atuantes durante a sedimentação (semi-árido), quando predominou a formação de esmectita (conforme resultados de amostras de subsuperfície).

A illita, terceiro mineral em frequência, decresce da Formação Adamantina (onde está presente em 1/3 das amostras) até os arenitos Caiuá (menos de 10\%). Esta distribuição geográfica decorre da relação entre a quantidade de illita e a distância da área-fonte. A medida em que se desloca de depósitos fluviais de borda para o sand sea (centro da bacia), a illita torna-se menos frequente entre os argilominerais, posto que tem origem detrítica.

Para análise dos resultados, determinou-se a frequência de ocorrência dos argilominerais, isto é, a relação entre o número de amostras onde o mineral foi identificado e o número total de amostras analisadas. Nas amostras provenientes de superfície - dos Grupos Caiuá e Bauru - a esmectita ocorre com valores em torno de 50\% nas Formações Rio Paraná, Santo Anastácio e Adamantina. Na Formação Goio Erê, atinge quantidade ao redor de $70 \%$, provavelmente devido à preservação do argilomineral pela cimentação carbonática, frequente na unidade, que inibiu a ação dos processos intempéricos. A esmectita é ainda o argilomineral dominante na Formação Rio Paraná em subsuperfície, onde alcança cerca de $90 \%$ de frequência de ocorrência. 

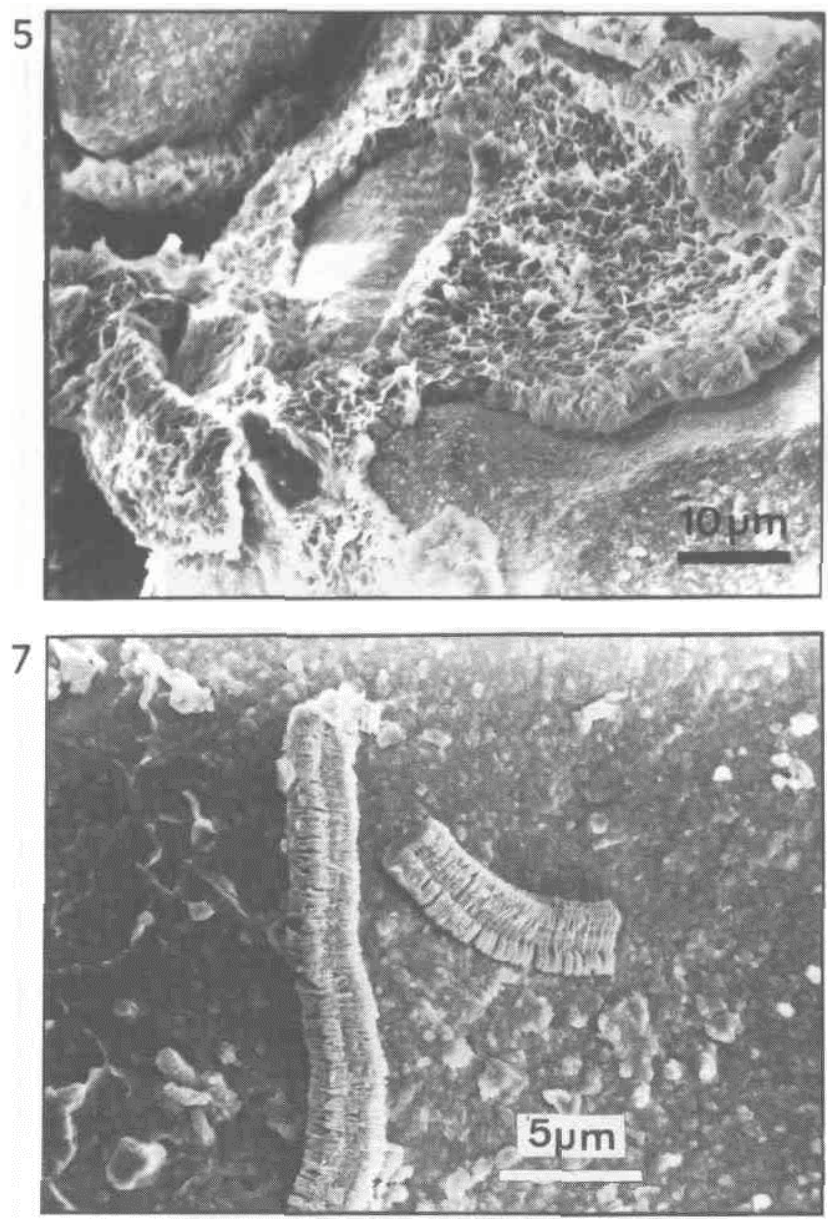

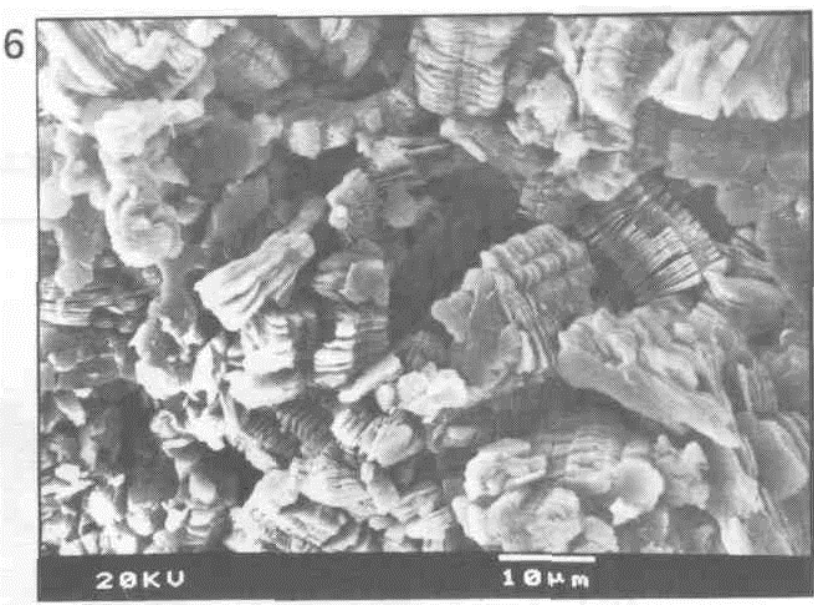

8

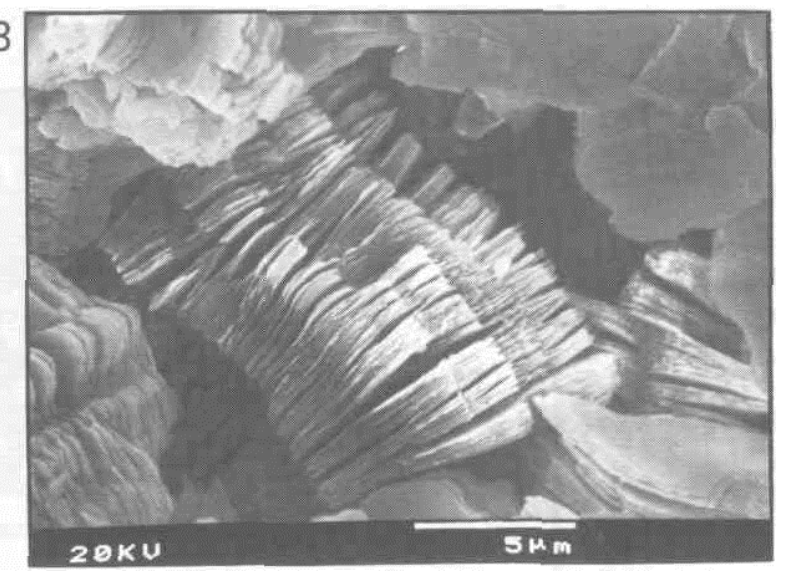

Prancha 2 -Foto 5. Esmectita autigênica revestindo grãos detríticos. Imagem obtida em M.E. V. Formação Goio Erê, amostra de superfície (Goio Erê, PR). Foto 6. Caulinita. Imagem de M.E.V. Formação Adamantina, amostra de superficie (Santo Inácio, PR). Foto 7. Caulinita vermiforme. Imagem de M.E.V. Formação Santo Anastácio, amostra de superfície (Pontal do Paranapanema, SP). Foto 8. Caulinita vermiforme. Imagem obtida em M.E. V. Formação Adamantina, amostra de superficie (Santo Inácio, $P R$ )

Plate 2 - Photo 5. Authigenic smectite pore lining. SEM image of outcrop sample of Goio Erê Formation (Goio Erê, Paraná State). Photo 6. Kaolinite. SEM image of outcrop sample of Adamantina Formation (Santo Inácio, Paraná State). Photo 7. Vermicular kaolinite. SEM image of outcrop sample of Goio Erê Formation (Goio Erê, Paraná State). Photo 8. Vermicular kaolinite. SEM image of outcrop sample of Adamantina Formation (Santo Inácio, Paraná State)

A caulinita aparece com frequência de 10 a $15 \%$ nas amostras de subsuperfície da Formação Rio Paraná, valor que aumenta para 50 a $70 \%$ nas amostras de superfície de todas as unidades, denotando sua origem claramente intempérica.

Possíveis arranjos em camadas mistas, mal desenvolvidos, foram identificados por análise de raios $\mathrm{X}$, apenas entre amostras de superficie. Provavelmente constituem produtos de intemperismo superficial.

\section{EVOLUÇÃO DIAGENÉTICA DOS ARENITOS EÓLI-} COS DÂ FORMAÇÃO RIO PARANÁ De modo geral, verifica-se que as transformações diagenéticas a que se submeteram os sedimentos da Formação Rio Paraná foram pouco intensas, tendo-se atingido estágios iniciais da mesodiagênese. Os vestígios de compactação química são menos comuns, possivelmente por ter sido parcialmente refreada pela cimentação carbonática. $\mathrm{O}$ desenvolvimento de porosidade secundária é frequente. Na figura 4 e na prancha 3 , são ilustrados os principais processos diagenéticos e feições observadas.

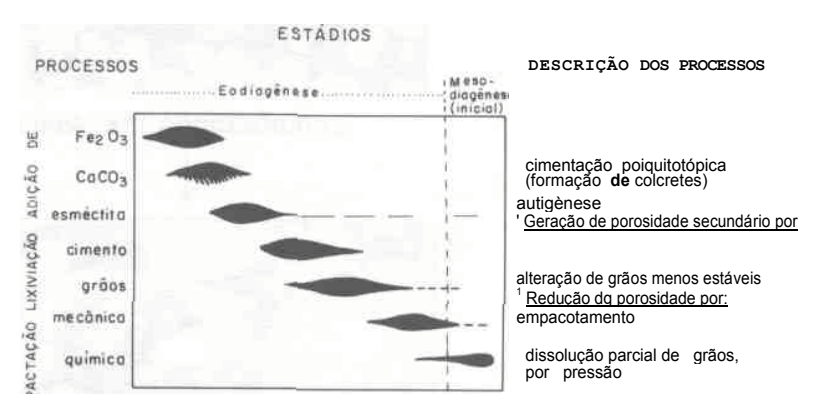

Figura 4 - Principais fases e processos diagenéticos identificados em arenitos da Formação Rio Paraná

Figure 4 - Main phases and diagenetic process identified in the Rio Paraná sandstones

Processos relacionados ao estágio de eodiagênese Após a deposição, os sedimentos da Formação Rio Paraná foram submetidos a processos eodiagenéticos: 

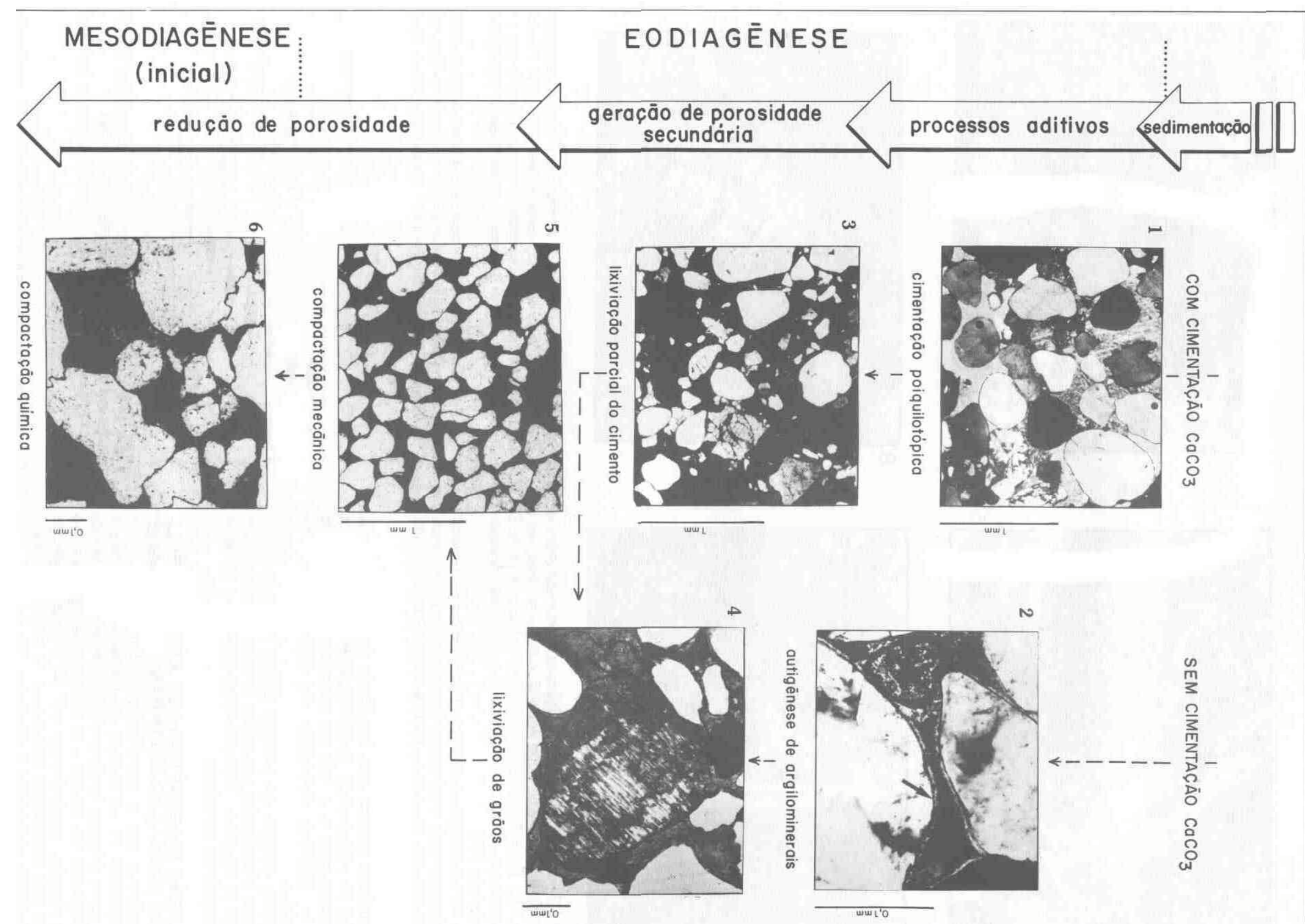
Prancha 3 -Modificações diagenéticas verificadas em arenitos da Formação Rio Paraná, por análise de seções delgadas e por M.E.V Informações complementares: 1 CIMENTAÇÃO POIQUILOTÓPICA: Formação de calcretes, na diagênese precoce, por cimentação carbonática. Fotomicrografia de seção delgada de arenito quartzoso, com nicóis cruzados. Base da Formação Rio Paraná, amostra de subsuperficie (UHE Porto Primavera, SP). 2.AUTIGENESE DE ARGILOMINERAIS: Revestimento de poros por argila. Fotomicrografia de seção delgada de arenito quartzoso, com nicóis cruzados. Amostra de superficie (Porto Rico, PR). 3. LIXIVIAÇÃO PARCIAL DO CIMENTO: remoção do cimento calcifico poiquilotópico, exibindo grão de feldspato substituido por $\mathrm{CaCO}_{3}$. Fotomicrografia, seção delgada de arenito quartzoso subarcoseano, com nicóis cruzados. Base da Formação Rio Paraná, amostra de subsuperfície (UHE Porto Primavera, SP). 4. LIXIVIAÇÃO DE GRÃOS: Grão de feldspato em avançado estado de alteração ("esqueletos"). Fotomicrografia de seção delgada de arenito quartzoso subarcoseano, com nicóis descruzados. Amostra de superficie (Paranavaí, PR). 5. COMPACTAÇAO MECÂNICA: Empacotamento de grãos sem "soldagem " nas superficies de contato. Fotomicrografia, seção delgada de arenito quartzoso, com nicóis descruzados. Amostra de subsuperficie (UHE Porto Primavera, SP). 6. COMPACTAÇAO QUÍMICA: Recristalização e "soldagem" em contatos intergranulares suturados. Notar que a porosidade secundária tem dimensões semelhantes às dos grãos, criando aparente paradoxo: arcabouço aberto, devido à lixiviação de grãos minerais menos estáveis, ao lado de feições de pressão e recristalização. Fotomicrografia, seção delgada de arenito quartzoso, com nicóis descruzados. Amostra de subsuperficie (UHE Porto Primavera, SP)

Plate 3 - Diagenetic modifications observed in Rio Paraná Formation sandstones by thin section analysis and SEM images. Further Information: 1. POIKILOTOPIC CEMENTATION: calcrete formation by carbonaceous cementation. Photomicrography of thin section of quartz sandstone, crossed nicóis. Subsurface sample of the base of Rio Paraná Formation (Porto Primavera Hydroelectric Plant, São Paulo State). 2. CLAY MINERAL AUTHIGENESIS: Pore lining by clay. Photomicrography of thin section of quartz sandstone, crossed nicóis. Outcrop sample (Porto Rico, Paraná State).

3. CEMENT PARTIAL REMOVAL: Calcitic poikilotopic cement removal, showing a feldspar grain replaced by $\mathrm{CaCO}_{3}$. Photomicrography of thin section of arcose quartz sandstone, crossed nicóis. Subsurface sample of the base of Rio Paraná Formation (Porto Primavera Hydroelectric Plant, São Paulo State).

4. GRAIN REMOVAL: Feldspar grain at advanced stage of decomposition (skeletal feature). Photomicrography of thin section of subarcose quartz sandstone, uncrossed nicóis. Outcrop sample (Paranavaí, Paraná State). In photo 6 of this plate an apparent incoherence: sutured contacts are present side by side to pores of grain dimensions. In fact, they are pores created by the change and removal of unstable minerais. 5. MECHANIC PACKING: Grain packing, without "soldering" in contact surfaces. Photomicrography of thin section of quartz sansdtone, uncrossed nicóis. Subsurface sample (Porto Primavera Hydroelectric Plant, São Paulo State). 6. CHEMICAL PACKING: Recristallization and "soldering" in intergranular contacts (sutured). Notice that the secundary porosity hás dimensions similar to the grains. Photomicrography of thin section of quartz sandstone, uncrossed nicóis. Subsurface sample (Porto Primavera Hydroelectric Plant, São Paulo State)

a. aditivos: revestimento dos grãos por película de óxido de ferro; desenvolvimento de calcretes na forma de solos calcificados (cimentação), nódulos e crostas de carbonato de cálcio antes do soterramento (Foto 1, Prancha 3); e autigênese de esmectita (Foto 2, Prancha 3). A formação de calcretes deu-se quando os depósitos estiveram sujeitos a oscilações do nível freático (águas alcalinas) e intensa evapotranspiração com precipitação de sais. Tal processo é mais efetivo nos depósitos marginais do sand sea, como os periféricos (Fm. Goio Erê) e extradunas (Fm. Santo Anastácio). Os depósitos mais interiores raramente exibem feições associadas à deposição em ambiente aquoso ou úmido, provavelmente devido às condições de maior aridez e de maior profundidade do nível freático. Quando da ausência de cimentação carbonática poiquilotópica, tem-se a neoformação de esmectita nos espaços intergranulares, como revestimento dos grãos;

b. de geração de porosidade secundária: lixiviação parcial (Foto 3, Prancha 3) ou total do cimento carbonático, ou ainda formação de porosidade móldica por alteração e remoção de grãos de minerais menos estáveis como feldspatos (Foto 4, Prancha 3) ou fragmentos líticos (basaltos); c. de redução inicial da porosidade por compactação mecânica do arcabouço. Nas amostras analisadas, verificou-se a predominância de contatos entre grãos dos tipos flutuante, pontual e planar (Foto 5, Prancha 3).

\section{Processos relacionados com mesodiagênese}

A evolução diagenética dos arenitos da Formação Rio Paraná atingiu estágios iniciais de mesodiagênese, registrados, com menor frequência, por feições de incipiente compactação química (contatos côncavo/convexos e suturados, Foto 6 da Prancha 3).

Ressalta-se que a cimentação carbonática precoce aparentemente protegeu partes do arcabouço do empacotamento, sugerida pela ocorrência de textura de grãos "flutuantes" em cimento carbonático poiquilotópico, mesmo em amostras de subsuperficie. Em alguns casos, amostras retira- das de testemunhos de sondagens provenientes de porções basais apresentaram arcabouço menos compactado que outras de posições superiores.

$\mathrm{O}$ estágio diagenético atingido indica baixos incrementos de temperatura e pressão (soterramento pouco profundo), sob pacote sedimentar pouco espesso. Tais resultados são coerentes com o caráter de bacia ampla e rasa, cuja espessura máxima de sedimentos atualmente preservados é estimada em 320 metros.

SILICIFICAÇÃO Localmente, as rochas foram afetadas por processos de silicificação de origem hidrotermal, provavelmente relacionados com o magmatismo alcalino neocretáceo/terciário (Fernandes et al. 1993). A silicificação atingiu, simultaneamente, unidades litoestratigráficas distintas, em geral quando estas se encontravam no estágio eodiagenético.

CONCLUSÕES Os argilominerais mais frequentes em arenitos do Grupo Caiuá são esmectita e caulinita. A illita detrítica ocorre em quantidades subordinadas, mais frequentemente na Formação Adamantina (Grupo Bauru). Esta última unidade ocupa posição marginal na área do estudo, mais próxima da área-fonte.

Esmectita autigênica é o argilomineral predominante em subsuperfície, conforme verificado nas amostras da Formação Rio Paraná. Sua frequente associação com cimentação e concreções carbonáticas (calcretes eodiãgenéticos) reflete condições deposicionais de pouca circulação de água (de $\mathrm{pH}$ alcalino), como as encontradas em áreas de sabkhas continentais. O contexto paleogeográfico e paleoclimático admitido para as unidades litoestratigráficas da área do estudo condiz com tal interpretação. Assim, a autigênese verificada nos arenitos estudados ocorreu na fase de diagênese precoce, formando essencialmente esmectita.

Quanto a aspectos diagenéticos, os arenitos da Formação Rio Paraná foram submetidos a transformações pós-sedi- 
mentares pouco intensas, tendo-se atingido apenas estágios iniciais de mesodiagênese.

A caulinita, dominante nas amostras de superfície de todas as unidades estudadas, formou-se por alteração devido ao intemperismo superficial.
Agradecimentos Os autores agradecem ao geólogo Jairo de Sant'Anna Taddeo (IPT) por análises e interpretação de resultados de raios $\mathrm{X}$, assim como à geóloga Cristina Miranda Menezes (ex-estagiária do IPT), pelo acompanhamento na revisão dos resultados apresentados neste texto.

\section{REFERÊNCIAS BIBLIOGRÁFICAS}

FERNANDES, L.A. 1992. A Cobertura Cretácea Suprabasâltica no Paraná e Pontal do Paranapanema (SP): os Grupos Bauru e Caiuá São Paulo. 129 p. (Dissertacão de Mestrado, IG-USP).

FERNANDES, L A. COIMBRA, A.M.; BRANDT NETO, M. 1993.

Silicificação hidrotermal neocretácea na porção meridional da Bacia

MANUSCRITO A798

Bauru. Rev. Inst. Geol, 14(2): 19-26. 